\title{
Motivational Embodied Conversational Agent for Brain Injury Rehabilitation
}

\author{
Judith HOCKING ${ }^{\mathrm{a}, 1}$ and Anthony MAEDER ${ }^{\mathrm{a}}$ \\ ${ }^{a}$ Flinders Digital Health Research Centre and Caring Futures Institute, College of \\ Nursing and Health Sciences, Flinders University, Adelaide, Australia
}

\begin{abstract}
The design and development of a motivational embodied conversational agent for brain injury rehabilitation is discussed. Results for initial prototype design and implementation, and alpha and beta testing phases are presented. Key aspects identified during development included supporting user engagement via personalization and choice-making; integrating behaviour change principles into dialogues; addressing clinical needs of cognitive fatigue and memory loss within conversation structure; and optimizing feasibility of use in a real-life clinical setting.
\end{abstract}

Keywords. Conversational agent, brain injury rehabilitation, behaviour change

\section{Introduction}

The design and development of a motivational embodied conversational agent (ECA) for brain injury rehabilitation, named 'RehabChat', is discussed here. A person with acquired brain injury (ABI) may experience complex symptoms both cognitive (e.g. memory, problem-solving) and physical (e.g. strength, balance). Recovery following ABI is often long-term over many years [1]. However, traditional human-delivered rehabilitation services are time limited, therefore novel approaches to care are warranted.

Clients with ABI can benefit from reiterative conversation of important clinical points, particularly goal setting and goal pursuit [2]. Additionally, increased client motivation is associated with improved engagement in therapy and overall clinical progress [3]. Using an ECA during brain injury rehabilitation could support recovery by enabling reiterative motivational conversations about goal setting and goal pursuit, with specific focus upon rehabilitation decision-making processes. Our research aims to investigate whether conversational agent based therapeutic support can be effective in rehabilitation for adults with ABI. Specifically, the ECA will be developed to address time/availability constraints in the health system and/or to provide alternative convenience/motivation aspects for subjects.

We present findings from initial stages of development for the RehabChat ECA, comprising design and implementation of the initial ECA prototype, followed by alpha and beta testing phases. The conversation dialogues in the ECA prototype are configured to include rehabilitation goal-oriented processes and related motivational support, and to accommodate the clinical needs of clients with ABI. The research context is ambulatory

\footnotetext{
${ }^{1}$ Corresponding Author, Judith Hocking, Flinders Digital Health Research Centre, College of Nursing and Health Sciences, Flinders University, GPO Box 2100, Adelaide SA 5001, Australia; E-mail: judith.hocking@flinders.edu.au.
} 
care rehabilitation for adults with a specific type of ABI, traumatic brain injury (TBI). The ECA will subsequently be refined with focus group consultations and deployed in a pilot trial to establish feasibility and usability, in collaboration with two local brain injury rehabilitation clinics.

\section{Developing the Embodied Conversational Agent}

The first stage of this project was to develop an initial ECA prototype relevant to the clinical setting of brain injury rehabilitation. This entailed selecting appropriate motivational behaviour change models for incorporation in the ECA, and a suitable ECA software platform. The ECA would be implemented by devising a motivational conversation generation process which followed the main tenets of these adopted models.

\subsection{Choice of motivational behaviour change models}

Motivation was identified as a central design aspect for the ECA because of its key importance for enhancing engagement in rehabilitation after brain injury [3]. As well, it has been identified that the design of digital health interventions for people with ABI should include motivational aspects [4]. Persuasive techniques are widespread in digital technology design [5] but are not designed for targeting at health purposes, where the subtleties of patient circumstances differentiate them from consumer applications.

Specific motivational behaviour change models integrated into the ECA were chosen from ABI and stroke literature as ABI-specific literature is comparatively limited, and stroke is a similar diagnosis. The two models chosen were motivational interviewing (MI), a therapeutic conversation approach [6], and self-determination theory (SDT), a theoretical model for key elements of personal wellbeing and motivation [7]. Secondary research review findings show efficacy of SDT [8] and of MI [9] in varied health settings.

More specifically, both MI and SDT have been recommended for brain injury rehabilitation [4] and are compatible between themselves [10]. Benefits of incorporating more than one behavioural change model has been demonstrated for stroke rehabilitation [11], and for use of an ECA for healthy lifestyle choices [12]. Notably, MI and SDT have been adapted for other digital interventions: for example, SDT as the methodological basis for developing person-centred digital technologies [13], and MI as the model used in ECA prototypes for promoting healthy lifestyles [12] and stress reduction [14].

\subsection{Capabilities of the ECA software platform}

The ECA software selected was Conversagent, a commercial product of Clevertar Pty Ltd https://www.clevertar.com/, based on its affordability and availability of ongoing supplier support. It has previously been used for comparable health purposes e.g. Cognitive-Behavioural Therapy [15]. Figure 1 depicts the humanoid avatar used to provide the embodiment aspect from the chosen software in the RehabChat user interface.

The Conversagent software enables a fully determined, seamless conversation experience to be designed. The avatar speaks the preconfigured conversation content that has been devised for the ECA, and the ECA user interface displays the text equivalent of what has been spoken. The overall ECA conversation can be composed of separate smaller conversations, or sub-conversations. Each sub-conversation is composed of dialogues which are passages or stubs of the sub-conversation. Sub-conversations can be 
configured to link together as needed. The sub-conversations can be purposed for specific focus areas of the overall conversation. For RehabChat, sub-conversations were developed for distinct areas of goal setting and goal pursuit: for example, choosing a rehabilitation priority to set as the main goal, and practising the home exercise program.

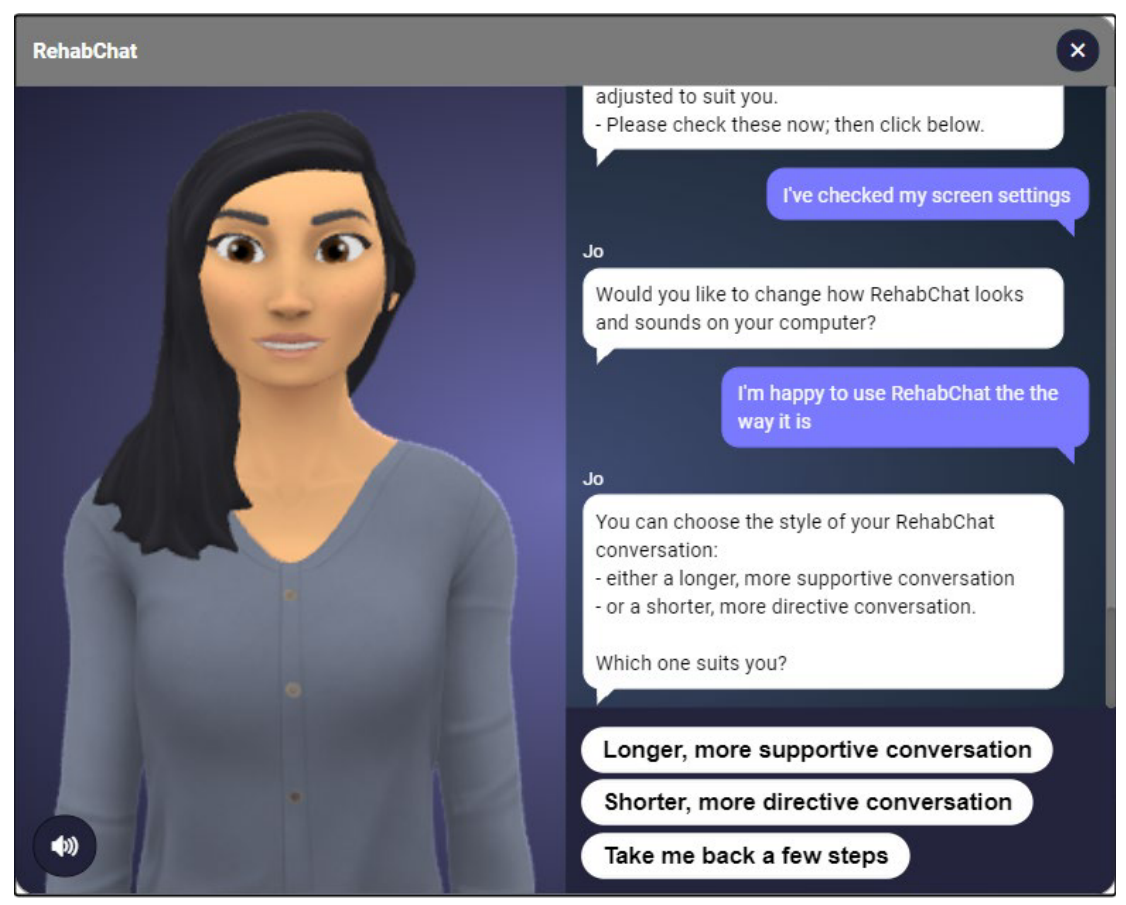

Figure 1. RehabChat user interface showing humanoid avatar and sample dialogue

\subsection{Designing the initial ECA prototype}

The overall ECA conversation was developed based upon feedback received at two health provider stakeholder meetings held at the collaborating rehabilitation service in 2019 , together with the expertise of the first author who has worked in ABI rehabilitation, and also with reference to rehabilitation goal-setting literature [16, 17]. The overall ECA conversation is intended to enable the user to identify and confirm a rehabilitation goal, and relevant home program, through participating in a MI- and SDT-styled conversation.

The ECA prototype dialogues were created using pre-determined language capabilities of the ECA software. Whilst this may seem to be a limitation of this study, the use of constrained language offered the benefit of controlling the nature of the intervention and provided a distinctive form to which the co-design process could respond. Specific technical capabilities of the ECA software which impact upon the development of sub-conversations and dialogues are presented below. Table 1 presents an example of a dialogue string to illustrate how Conversagent dialogues are structured. 
Table 1. Example series of conversation dialogues

\begin{tabular}{|c|c|c|}
\hline Content & Components & Follow-on \\
\hline $\begin{array}{l}\text { 'Your goal [user name] - next you will } \\
\text { develop a goal for your rehab. } \\
\text { First, choose a rehab priority below } \\
\text { that you'll focus on for the next } 6 \\
\text { weeks. } \\
\text { It needs to be one that your } \\
\text { [therapist/professional] can supervise. } \\
\text { : Physical (e.g. strength, balance) } \\
\text { : Language (e.g. speaking, reading) } \\
: \text { Thinking (e.g. planning, problem } \\
\text { solving) ...' }\end{array}$ & $\begin{array}{l}\text { A) Pre-set variables } \\
\text { : in [square brackets] } \\
\text { : auto-populate with freeform } \\
\text { text entered by user in earlier } \\
\text { dialogue } \\
\text { : (in this example) are for } \\
\text { user's name and supervising } \\
\text { therapist's profession. } \\
\text { B) Multiple choice options are } \\
\text { provided. }\end{array}$ & $\begin{array}{l}\text { : User selects one option. } \\
\text { : Based on user's choice, ECA will } \\
\text { jump to next dialogue } \\
\text { : For this example, user chooses } \\
\text { 'Physical' and is directed to next } \\
\text { dialogue shown below. }\end{array}$ \\
\hline $\begin{array}{l}\text { 'Please describe your Physical priority } \\
\text { area in your own words. Complete the } \\
\text { sentence below: } \\
\text { My Physical priority area for the next } \\
6 \text { weeks is ... (up to } 10 \text { words)' }\end{array}$ & $\begin{array}{l}\text { A) User is cued to enter } \\
\text { freeform text (up to } 10 \text { words). } \\
\text { : User enters text in text box } \\
\text { with a placeholder statement of } \\
\text { 'Describe physical rehab } \\
\text { priority in own words' } \\
\text { B) User clicks 'Send'. }\end{array}$ & $\begin{array}{l}\text { : ECA saves the freeform text } \\
\text { entered as a variable [rehab } \\
\text { priority] } \\
: \text { the user is directed to the next } \\
\text { dialogue shown below. }\end{array}$ \\
\hline $\begin{array}{l}\text { 'Why is your rehab priority of [rehab } \\
\text { priority] important to you? } \\
\text { Please choose an option below. } \\
\text { : Increased fitness } \\
\text { : More independence } \\
\text { : Manage fatigue } \\
\text { : Be more connected } \\
\text { : Something else' }\end{array}$ & $\begin{array}{l}\text { A) Variable of [rehab priority] } \\
\text { populates with freeform text } \\
\text { entered by user (see above) } \\
\text { B) User selects one multiple- } \\
\text { choice option }\end{array}$ & $\begin{array}{l}\text { : If user selects 'Something else' } \\
\text { they are directed to next dialogue } \\
\text { for entering freeform text to } \\
\text { populate variable of [priority's } \\
\text { importance] } \\
\text { : If user selects one of first } 4 \\
\text { options, this wording is saved as } \\
\text { variable [priority's importance] }\end{array}$ \\
\hline
\end{tabular}

Use of the Conversagent platform enabled various ways to structure how conversations were linked, and how dialogues were created. This flexibility enabled matching to the specific purposes of MI and SDT, for addressing goal-oriented needs.

- Separate sub-conversations for different stages of the rehabilitation process were developed for: goal-setting, identifying support resources; home program details; half-way progress review; final progress review.

- Two styles of conversation content - one with more discursive, supportive dialogues, and the other with briefer, more directive interactions - were designed. For each content style, the full process of goal setting was covered; however, the briefer style had less emphasis on MI and SDT aspects.

- The sub-conversations within each style were linked together using the option to join another sub-conversation. Using this approach allowed for a seamless experience for the user, and also enabled much easier management for the designer as smaller chunks of discrete conversation are easier to edit and review.

- Each dialogue was structured as either a comment or as a question to which the user would respond. User response options were either to select a choice (yes/no, multiple choice) or to enter free-form text up to a pre-designated maximum number of words. Having a maximum word count avoided the overhead of dealing with open-ended unfocussed responses which could cause the conversation to deviate from the model-based overall structure. This approach has been successfully applied in a conversational agent to assess alcohol abuse [18]). Free-form text responses were saved as variables (e.g. user's name, main goal) which could be inserted at relevant points in the dialogues. 
Each dialogue is linked to another dialogue by pre-determined logic decisions. A dialogue can be configured to have multiple forward-joining options attached to it. Any of these options is activated according to a set precursor, commonly if the user selects a distinct multiple-choice option.

\section{Integrating Motivation and Clinical Paradigms}

There were three key paradigms integrated into the design of the ECA. These were motivational behaviour change; needs of clients with TBI; and clinical goal-setting.

\subsection{Motivational behaviour change models integrated into the conversation design}

Motivational interviewing as a therapeutic conversation model supports the client to reflect upon and articulate their needs/priorities, relevant goal/s, and opportunities and barriers to success. As well, MI is tolerant of resistance to change, and supportive during setbacks in progress [6]. These aspects have been integrated into the design of the ECA through by using a sequence for the questions which follows ideation of a rehabilitation priority, development of a goal, planning for resources needed to achieve goal, practicing required tasks to achieve the goal, and reviewing progress towards goal achievement.

Self-determination theory expounds that there are three inherent human needs of connectedness (relating meaningfully with others), autonomy (opportunity to make decisions for oneself) and competency (perform activities for which one perceives having enough ability) [7]. When these three needs are met, a person is more likely to feel motivated to achieve their given goals. These three needs have been integrated into the ECA through offering autonomous decision-making for goal-setting and in identifying support resources. Competency is supported through ensuring that the goal meets the client's perception of what they can likely achieve in the time period of the intervention, and the type of resources they will need to ensure they have enough support to achieve their goal. Connectedness is promoted by maintaining a regular connection with their key therapist who provides clinical oversight during initial use of the ECA; and through the client identifying a support person to provide them help during their rehabilitation.

\subsection{Clinical needs supported in conversational style}

The design of RehabChat has been purposefully focused upon meeting the clinical needs of a distinct client group: adults with TBI. Conversational agents have been similarly designed to meet the specific needs of a client group including to provide memory support for memory loss [19], and care for clients with mental health needs [20].

Adults with TBI can experience varied clinical symptoms including pain, fatigue, dizziness, and cognitive changes such as decreased memory and impaired insight. It is imperative that the ECA conversation dialogues avoid exacerbating fatigue, and that they support memory and other cognitive needs. These aspects have been integrated through offering multiple choice options to reduce cognitive fatigue; and providing reiteration and interim summaries of items discussed to support memory challenges.

It is necessary to support the physiological process of neuroplasticity during rehabilitation. Neuroplasticity is the process by which a person continues to develop new brain connections enabling learning of new skills throughout the lifespan [21]. 
Neuroplasticity following brain injury allows for recovery during rehabilitation; supporting neuroplasticity during rehabilitation is achieved by the client practising motivational tasks [22]. RehabChat provides motivation-based conversation for the user to practise their home program tasks related to their motivational rehabilitation goal.

\subsection{Rehabilitation goal setting processes represented in conversation dialogues}

RehabChat incorporates key aspects of goal setting [17] and ensuring goals are specific and measurable [16]. It has been specifically designed for clinical rehabilitation, and to be minimally intrusive upon the usual rehabilitation approaches used in the clinics.

- Rehabilitation goal-setting focusses upon client-centred goals formed through exploring the client's clinical needs and personally motivating aspirations for recovery. Clinical oversight is essential in goal-setting to ensure the goals are feasible and safe. This is particularly important when trialing a novel clinical tool. Clinician oversight will be included in the feasibility pilot trial.

- Specific dimensions for rehabilitation goal setting incorporate the components of Specific, Measurable, Achievable, Relevant, Time-limited (SMART) [5]. RehabChat is intended to be pilot trialed in a clinic setting alongside usual care, and to require minimal time and concentration from both the client, and the clinician. These purposes are achieved by matching the ECA dialogues to existing SMART goal-setting paradigms already used within the clientclinician alliance. As in usual practice, the client and clinician will work together to determine specific prescribed exercises to support goal-attainment, which will be practiced at home. These exercises are entered into the ECA and then serve as the basis for subsequent ECA dialogues for times of home practice.

\section{Conducting Testing of the RehabChat Prototype}

The ECA prototype has undergone alpha $(n=3)$ and beta $(n=11)$ testing phases. These results from alpha and beta testing are part of the software development process and are opinions contributed voluntarily by colleagues from the workplace and are not from a research study based on independent recruitment and consented data collection. For the alpha and beta testing, inhouse participants included health professionals familiar with the demographics of typical subjects envisaged and with the use of conversational therapies. Participants were emailed a URL for RehabChat, a User Guide, and a Feedback Form containing specific questions. Participants emailed their response feedback, after using the ECA for a suitable time period (range $=15-30$ minutes). Main feedback results from alpha and beta testing are presented below and summarized in Table 2 and Table 3 respectively.

\subsection{Alpha testing}

The primary purpose of alpha testing was to establish if the prototype ECA was robust, and if it did what it was purposed to do. Five questions were asked:

What went well?

What didn't go well?

What suggestions would you like to make for improving the ECA? 
Any other comments?

Could you 'break' the ECA? If so how?

Three senior academic researchers of the Flinders Digital Health Research Centre completed alpha testing. Feedback was collated, and changes were made to the ECA in response to the feedback where feasible. All changes accorded to the principles of MI and SDT and were observant of the clinical needs of clients.

Results from alpha testing confirmed that the ECA software was easy to launch and use. The results also highlighted areas needing to be optimised including supporting client choice-making; allowing personalization of the ECA; and streamlining the conversation structure to minimize cognitive demand. Changes were made to address these feedback points. Table 2 provides an overview of alpha testing feedback and the design response changes made to the ECA. A key change amongst these was the inclusion of a shorter version of the conversation in addition to the longer more supportive version. The updated ECA prototype was subsequently used for beta testing.

Table 2. Alpha Testing Responses to Feedback

\begin{tabular}{|c|c|c|c|}
\hline Feedback domain & Feedback received & Design response & Reason \\
\hline Dialogue structure & $\begin{array}{l}\text { More multiple-choice } \\
\text { to decrease fatigue }\end{array}$ & $\begin{array}{l}\text { More multiple-choice at } \\
\text { key decision points }\end{array}$ & $\begin{array}{l}\text { User is aware of expected } \\
\text { input; lessens fatigue }\end{array}$ \\
\hline Dialogue structure & $\begin{array}{l}\text { More variety in } \\
\text { multiple choice }\end{array}$ & $\begin{array}{l}\text { Multiple choice options } \\
\text { have been diversified }\end{array}$ & $\begin{array}{l}\text { Supports detail in user's } \\
\text { thinking, \& user interest }\end{array}$ \\
\hline Dialogue styles & Use simple language & $\begin{array}{l}\text { Simplified to lower } \\
\text { secondary school level }\end{array}$ & Promotes understanding \\
\hline Personalization & $\begin{array}{l}\text { Able to choose a } \\
\text { humanoid avatar }\end{array}$ & Developed 2 avatar styles & Improves personalization \\
\hline Personalization & $\begin{array}{l}\text { An alternative } \\
\text { conversation style }\end{array}$ & $\begin{array}{l}2 \text { conversation styles with } \\
\text { same main content: } \\
\text { longer, supportive style; } \\
\text { shorter, directive style }\end{array}$ & $\begin{array}{l}\text { Client preference \& } \\
\text { clinical need considered }\end{array}$ \\
\hline Behavior change & $\begin{array}{l}\text { Integrate specific } \\
\text { aspects of behaviour } \\
\text { change paradigms }\end{array}$ & $\begin{array}{l}\text { Content includes choice- } \\
\text { making, meaningfulness } \\
\text { of goal, support resources }\end{array}$ & $\begin{array}{l}\text { These inclusions support } \\
\text { user's motivation }\end{array}$ \\
\hline
\end{tabular}

\subsection{Beta testing}

The purpose of beta testing was to test the working model of the ECA prototype and seek feedback on the overall concept and its conversation content, particularly in relation to its intended clinical application in brain injury rehabilitation. The Beta Feedback Form was developed based upon software design and client-specific factors. The software factors were derived from the WCAG main principles of Perceivable, Operable, Understandable and Robust [23]. Only the first three of these were applied; the Robust principle was not appraised due to RehabChat not yet being linked to other technologies.

The Beta Feedback Form therefore was comprised of three main sections: Interacting with the technology of RehabChat; Using RehabChat for motivation, goal setting and goal achievement; Potential use of RehabChat alongside usual rehabilitation care. These sections were composed of 12 questions and a fourth section was included for any other open comments. A separate User Guide was developed describing: the intended clinical setting and end-users for RehabChat; the need for clinician oversight; an overview of the process of beta testing; instructions to launch and use RehabChat. 
Table 3. Beta Testing: Themes and Main Categories

\begin{tabular}{|c|c|c|c|}
\hline Theme & \multicolumn{3}{|c|}{ Feedback referenced to participant $(\mathrm{P}) \&$ line number $(\mathrm{L})$} \\
\hline $\begin{array}{l}\text { Acceptability } \\
\& \text { usability in } \\
\text { clinic setting }\end{array}$ & $\begin{array}{l}\text { Acceptability: non-intrusive } \\
\text { (P4, L108); no personal } \\
\text { information needed ((P1, } \\
\text { L106) }\end{array}$ & $\begin{array}{l}\text { Accessibility: easy to } \\
\text { load \& get started (P4, } \\
\text { L109); only need 'a link' } \\
\text { (P3, L99) }\end{array}$ & $\begin{array}{l}\text { Integrate into clinic: 'very } \\
\text { easily' (P3, L100); need } \\
\text { clinician input (P1, L108); } \\
\text { 'I think this could easily } \\
\text { be used alongside usual } \\
\text { care as an extra support } \\
\text { mechanism' (P11, L95) }\end{array}$ \\
\hline $\begin{array}{l}\text { User } \\
\text { experience }\end{array}$ & $\begin{array}{l}\text { Navigation: navigation } \\
\text { seems quite intuitive (P11, } \\
\text { L23); liked option to go } \\
\text { back a few steps (P1, L24); } \\
\text { forward backward ok but } \\
\text { what if I want to jump a } \\
\text { section? (P9, L39) }\end{array}$ & $\begin{array}{l}\text { Typing responses: 'no } \\
\text { issues' (P1, L21); user } \\
\text { may need help; have } \\
\text { more multiple-choice } \\
\text { options (P4, L26); typing } \\
\text { for me is easy, but I } \\
\text { wonder about the BI } \\
\text { population? (P9, L36) }\end{array}$ & $\begin{array}{l}\text { HCI: clear, easy to read } \\
(\mathrm{P} 1, \mathrm{~L} 16) \text {; easy to hear, } \\
\text { good pace }(\mathrm{P} 3, \mathrm{~L} 16)\end{array}$ \\
\hline $\begin{array}{l}\text { Motivation \& } \\
\text { behavior } \\
\text { change }\end{array}$ & $\begin{array}{l}\text { Make choices: 'to some } \\
\text { extent, when you can enter } \\
\text { text, but less so when } \\
\text { clicking the response } \\
\text { buttons' (P1, L99); to an } \\
\text { extent - dependent on } \\
\text { relationship with MDT (P8, } \\
\text { L51) }\end{array}$ & $\begin{array}{l}\text { Promote self-managing: } \\
\text { yes, because user- } \\
\text { focused (P3, L107); } \\
\text { 'really think about } \\
\text { yourself' (P7, L48) }\end{array}$ & $\begin{array}{l}\text { Supports motivation: } \\
\text { through goal setting (P2, } \\
\text { L63); 'Provides support } \\
\text { when needed, helps to set } \\
\text { goals and review goals, } \\
\text { keeping client motivated } \\
\text { and on track.' (P10, L64) }\end{array}$ \\
\hline $\begin{array}{l}\text { Clinical } \\
\text { relevance \& } \\
\text { use }\end{array}$ & $\begin{array}{l}\text { Communicate with } \\
\text { therapist: 'encouraging the } \\
\text { user to follow-up with their } \\
\text { therapist' (P1, L62); 'if the } \\
\text { therapist could see the data } \\
\text { entered that would be } \\
\text { helpful' (P1, L70) }\end{array}$ & $\begin{array}{l}\text { Support rehabilitation: } \\
\text { 'Definitely, clear goals } \\
\text { are the focus' (P4, L98); } \\
\text { Enables client to review } \\
\text { progress - revisit goals. } \\
\text { (P10, L72) }\end{array}$ & $\begin{array}{l}\text { Practice home tasks / } \\
\text { exercises: 'looks like a } \\
\text { good process' (P6, L77); } \\
\text { 'need more breakdown of } \\
\text { the tasks.' (P3, L74) }\end{array}$ \\
\hline $\begin{array}{l}\text { Ideas for } \\
\text { future design } \\
\text { changes }\end{array}$ & $\begin{array}{l}\text { Goal setting: set measurable, } \\
\text { specific goals (P5, L99); } \\
\text { 'More guidance could be } \\
\text { provided in development of } \\
\text { goals' (P10, L113) }\end{array}$ & $\begin{array}{l}\text { User interface: 'It would } \\
\text { be enhanced with more } \\
\text { audio, visual and } \\
\text { interactive capabilities if } \\
\text { possible.' (P3, L122) }\end{array}$ & $\begin{array}{l}\text { Give feedback: 'More } \\
\text { intervals than just } \\
\text { baseline, halfway and after } \\
\text { the program.' (P3, L60); } \\
\text { may need to screen for } \\
\text { suitability (P9, L111) }\end{array}$ \\
\hline $\begin{array}{l}\text { Browser \& } \\
\text { computer } \\
\text { used; ECA } \\
\text { performance }\end{array}$ & $\begin{array}{l}\text { Browser: Chrome (9); Safari } \\
\text { (1); Explorer (1) }\end{array}$ & $\begin{array}{l}\text { Computer: laptop (5); } \\
\text { desktop (6) }\end{array}$ & $\begin{array}{l}\text { Performance: 'Good, no } \\
\text { glitches or complications } \\
\text { with the RehabChat itself.' } \\
\text { (P3, L45) }\end{array}$ \\
\hline $\begin{array}{l}\text { Technical } \\
\text { issues }\end{array}$ & $\begin{array}{l}\text { Avatar speaks some } \\
\text { punctuation e.g. says dash } \\
\text { for - (P6, L133) }\end{array}$ & $\begin{array}{l}\text { Some entered content not } \\
\text { populating later } \\
\text { dialogues }(\mathrm{P} 6, \mathrm{~L} 31)\end{array}$ & $\begin{array}{l}\text { Connections between } \\
\text { dialogues at times not } \\
\text { logical }(\mathrm{P} 2, \mathrm{~L} 174)\end{array}$ \\
\hline
\end{tabular}

Potential participants invited for beta testing were Flinders University $\mathrm{PhD}$ candidates or academic staff affiliated with the Flinders Digital Health Research Centre, with experience in digital health technology and/or health care. Participants were requested to choose to provide feedback based on the perspective of either a clinician or that of a client. Eleven individuals ultimately participated.

Participant responses for beta testing were analysed using the Framework Analysis method [24] to develop a cohesive thematic model. This included: making initial coding notes on the completed Feedback Forms; defining likely themes and categories to best fit the coded data; and organizing the data under the themes and categories. Changes to 
the thematic model were made iteratively during analysis to optimise clarity in how data was organized. Beta testing themes and main categories are presented in Table 3.

Results from beta testing revealed that RehabChat functioned easily for users, and any ECA dialogue issues were the result of content configuration issues. Feedback recommendations for changes regarding clinical application and feasibility included: needing to enhance specific aspects of goal setting; allowing for more choice-making during progress reviews; and providing visual feedback on progress being made.

Following beta testing, the ECA was substantially modified to include more choice making, explicit collection of SMART goal-setting information, smoothing out of the conversation dialogues to read more easily, correcting design errors which had impeded correct linking of dialogues and inputting of variables; and clarification of the user guide and training process for users to receive prior to intended clinical use. This updated version of RehabChat will be used in the subsequent co-design workshops.

\section{Conclusion}

Early testing of the ECA prototype RehabChat has examined its clinical relevance and potential usability, and identified aspects requiring further development. The appropriateness of the conversation and dialogue structuring and the utility of the two style variants has been confirmed by this process. This testing phase has provided the basis for further intended refinement and extension of the ECA to be achieved through co-design workshops and a pilot trial. The next stages for developing the ECA prototype are firstly, to conduct a series of four co-design workshops with clients and clinicians of the collaborating brain injury rehabilitation clinics; and secondly, to conduct a feasibility and usability pilot trial at the same clinics over a six month period.

\section{Acknowledgements}

Judith Hocking is a $\mathrm{PhD}$ scholarship recipient from the Australian Research Council Industrial Transformation Research Hub for Digital Enhanced Living (IH170100013). Prof Anthony Maeder, Prof David Powers, A/Prof Belinda Lange, and Dr Lua PerimalLewis were involved in supervising this $\mathrm{PhD}$ study. Dr Martin Luerssen, Chief Technology Officer at Clevertar Pty Ltd, provided technical support for the use of Conversagent. Ms Bertha Nevada assisted in clarifying technical capabilities of the ECA software.

\section{References}

[1] Khan F, Baguley IJ, Cameron ID. Rehabilitation after traumatic brain injury. Med J Aust. 2003;178(6):290-5.

[2] Webb PM, Glueckauf RL. The Effects of Direct Involvement in Goal Setting on Rehabilitation Outcome for Persons With Traumatic Brain Injuries. Rehabil Psychol. 1994;39(3):179-88.

[3] Medley AR, Powell T. Motivational Interviewing to promote self-awareness and engagement in rehabilitation following acquired brain injury: A conceptual review. Neuropsychol Rehabil. 2010;20(4):481-508.

[4] Kusec A, Velikonja D, DeMatteo C, Harris JE. Motivation in rehabilitation and acquired brain injury: can theory help us understand it? Disabil Rehabil. 2019;41:2343-9. 
[5] Thomson C, Nash J, Maeder A. Persuasive design for behaviour change apps: Issues for designers. In: Blauw F, Coetzee M, Coulter D, Ehlers E, Leung W, Marnewick C, van der Haar, DT, editors. Proceedings of the 2016 Annual Research Conference of the South African Institute of Computer Scientists and Information Technologists (SAICSIT), 2016 Sep 26-28, Johannesburg, South Africa. New York (NY):ACM; 2016:Article 43;e1-10.

[6] Miller WR, Rollnick S. Motivational interviewing: Preparing people to change addictive behavior. New York, NY, US: The Guilford Press; 1991.p. 348

[7] Ryan RM, Deci EL. Self-Determination Theory and the Facilitation of Intrinsic Motivation, Social Development, and Well-Being. Am Psychol. 2000;55(1):68-78.

[8] Ng J, Ntoumanis N, Thogersen-Ntoumani C, Deci E, Ryan R, Duda J, Williams, G. Self-determination theory applied to health contexts: a meta-analysis. Psychol Health. 2012;7(4):325-40.

[9] Lundahl B, Moleni T, Burke BL, Butters R, Tollefson D, Butler C, et al. Motivational interviewing in medical care settings: A systematic review and meta-analysis of randomized controlled trials. Patient Educ Couns. 2013;93(2).

[10] Miller WR, Rollnick S. Meeting in the middle: motivational interviewing and self-determination theory. Int J Behav Nutr Phys Act. 2012; 9(25):2.

[11] Lewthwaite R, Winstein CJ, Lane CJ, Blanton S, Wagenheim BR, Nelsen MA, et al. Accelerating Stroke Recovery: Body Structures and Functions, Activities, Participation, and Quality of Life Outcomes From a Large Rehabilitation Trial. Neurorehabil Neural Repair. 2018;32(2):150-65.

[12] Bickmore TW, Schulman D, Sidner CL. A reusable framework for health counseling dialogue systems based on a behavioral medicine ontology. J Biomedical Inform. 2011;44(2):183-97.

[13] Peters D, Calvo RA, Ryan RM. Designing for Motivation, Engagement and Wellbeing in Digital Experience. Front Psychol. 2018;9(Article 797); 1-15.

[14] Park S, Choi J, Lee S, Oh C, Kim C, La S, et al. Designing a Chatbot for Brief Motivational Interview on Stress Management: Qualitative Case Study. J Med Internet Res. 2019;21(4):e12231.

[15] Sydney North Health Network. Introducing your free digital coach for anxiety \& depression. Chatswood, NSW: Sydney North Health Network; 2018 [accessed 9 June 2020]. Available from: https://sydneynorthhealthnetwork.org.au/mentalhealthtriage/low-intensity/healthy-minds-digitalcoach/.

[16] Bovend'Eerdt TJ, Botell RE, Wade DT. Writing SMART rehabilitation goals and achieving goal attainment scaling: a practical guide. Clin Rehabil. 2009;23(4):352-61.

[17] Plant SE, Tyson SF, Kirk S, Parsons J. What are the barriers and facilitators to goal-setting during rehabilitation for stroke and other acquired brain injuries? A systematic review and meta-synthesis. Clin Rehabil. 2016;30(9):921-30.

[18] Elmasri D, Maeder A. A conversational agent for an online mental health intervention. In International Conference on Brain Informatics and Health (BIH) 2016, Oct 13-16 2016, Omaha, NE, USA. Champaign, IL, USA:Springer; 2016. p. 243-51.

[19] Maeda H, Saiki S, Nakamura M, Yasuda K. Memory Aid Service Using Mind Sensing and Daily Retrospective by Virtual Agent. In: Duffy V. (eds) Digital Human Modeling and Applications in Health, Safety, Ergonomics and Risk Management. Healthcare Applications. HCII 2019. Lecture Notes in Computer Science, vol 11582: 353-364. Springer, Cham.

[20] Vaidyam AN, Wisniewski H, Halamka JD, Kashavan MS, Torous JB. Chatbots and ConversationalAgents in Mental Health: A Review of the Psychiatric Landscape. Can J Psychiatry. 2019;64(7):456-64.

[21] Voss P, Thomas ME, Cisneros-Franco JM, de Villers-Sidani É. Dynamic Brains and the Changing Rules of Neuroplasticity: Implications for Learning and Recovery. Front Psychol. 2017;8(1657):e1-11.

[22] Winstein RC, Lewthwaite BR, Blanton BS, Wolf BL, Wishart BL. Infusing Motor Learning Research Into Neurorehabilitation Practice: A Historical Perspective With Case Exemplar From the Accelerated Skill Acquisition Program. J Neurol Phys Ther. 2014;38(3):190-200.

[23] Eggert E, Abou-Zahra S. How to Meet WCAG (Quick Reference). A customizable quick reference to Web Content Accessibility Guidelines (WCAG) 2 requirements (success criteria) and techniques. 2019 [accessed 12 June 2020]. Available from: https://www.w3.org/WAI/WCAG21/quickref/.

[24] Furber C. Framework analysis: a method for analysing qualitative data. African Journal of Midwifery and Women's Health. 2010;4(2):97-100. 